\title{
Enteral Pancreatic-like Enzymes of Microbial Origin affect Insulin Release during an Intravenous Glucose Tolerance Test
}

\author{
Pierzynowski SG ${ }^{1-4 *}$, Goncharova $\mathrm{K}^{1,2,3,5}$, Woliński $\mathrm{J}^{2,3,5}$, Prykhodko $\mathrm{O}^{1}$, Weström $\mathrm{B}^{1}$ and Lozinska $\mathrm{L}^{1-3}$ \\ ${ }^{1}$ Department of Biology, Lund University, Lund, Sweden \\ ${ }^{2}$ Innovation Centre - Edoradca, Tczew, Poland \\ ${ }^{3}$ SGPlus, Malmo, Sweden \\ ${ }^{4}$ Department of Medical Biology, Institute of Rural Health, Lublin, Poland \\ ${ }^{5}$ Department of Endocrinology, Kielanowski Institute of Animal Nutrition and Physiology, Polish Academy of Sciences, Jabłonna, Poland
}

\begin{abstract}
We have previously shown that the presence of pancreatic enzymes in the gut lumen of exocrine pancreatic insufficient pigs influences blood glucose and insulin levels during an intravenous glucose tolerance test (IVGTT). The present study aims to highlight the effects of orally applied pancreatic-like enzymes on blood glucose and plasma insulin levels during an IVGTT in young intact pigs.

Five, 7-week old pigs were fed with pancreatic-like enzymes of microbial origin, a proteinase (from Aspergillus melleus), $\alpha$-amylase (from Aspergillus oryzae) or lipase (from Burkholderia cepacia) alone or in combination with the $\mathrm{Ca} / \mathrm{Na}$ salts of $\alpha$-ketoglutaric acid (AKG). One hour following administration of the various supplements an IVGTT was performed. Blood samples were withdrawn during the 2 hours of IVGTT for glucose and insulin analyses.

Blood glucose during the IVGTT was identical following administration of all combinations of the various enzymes or enzyme mixtures. Enteral loading of amylase or any amylase containing mixture resulted in reduced insulin secretion while administration of proteinase or any proteinase containing mixture resulted in enhanced insulin secretion during IVGTT, as compared to the control water vehicle. Lipase or AKG and lipase or AKG containing mixtures did not affect insulin secretion. Thus, it can be suggested that host amylase/protease ratio and their amount in pancreatic juice can participate in regulation of insulin release, thus, possibly affecting development of obesity and diabetes type 2 .
\end{abstract}

Keywords: $\alpha$-amylase; Proteinase; Insulin

\section{Introduction}

Insulin misregulation has considerable impact on health status [1]. Increased consumption of diets rich in carbohydrates and proteins results in the overproduction of insulin, leading to the development of insulin resistance and undesirable anabolic activity. Since the assimilation of nutrients is regulated in multiple stages, one possible way to improve insulin regulation would be to improve the clearance of glucose from the blood stream, in an insulin independent way. This could be achieved by using appropriate functional dietary supplements, which in turn could trigger alternative mechanisms of glucose assimilation. Results from previous studies in our lab have suggested that both pancreatic enzymes and AKG are involved in the regulation of blood glucose [2,3].

The role of pancreatic enzymes in the digestion of nutrients in the intestine is well studied and recognized. E.g., enzymatic activity of pancreatic $\alpha$-amylase is responsible for formation of postprandial hyperglycaemia $[1,4]$. However, the involvement of the pancreatic enzymes in the regulatory mechanisms responsible for the regulation of the postprandial glycaemia seems to be overlooked. Blood glucose regulation is believed to be accomplished mostly by the endocrine pancreas, liver and kidneys, as well as various gastrointestinal hormones which influence insulin secretion $[5,6]$. However, glucose intolerance, together with a delayed insulin release has been observed during exocrine pancreatic insufficiency in both humans and pigs $[3,7]$. Such changes are recognized as a pancreatogenic type of diabetes (type 3c) and are suggested to occur together with exocrine pancreatic insufficiency or pancreas injury [8]. In humans, the influence of pancreatic enzyme replacement therapy (PERT) on glucose metabolism remains controversial. Improved blood glucose control and reduced glycated haemoglobin, following PERT, has previously been observed [7,9]. However, other studies have observed no effect [10-12]. By using young pigs with induced exocrine pancreatic insufficiency, we found that the presence of pancreatic enzymes in the gut lumen resulted in improved direct utilization of blood glucose and improved growth performance, without reinforcing insulin release [3]. Thus, we were interested to investigate whether exogenous digestive enzymes could alter glucose tolerance or insulin response in healthy pigs, especially during the growth period, using microbial enzymes, which mimic endogenous digestive pancreatic enzymes and are widely available. We also hypothesized that another potential supplement, $\alpha$-ketoglutaric acid (AKG), could have an impact on post-loading glycaemic control, based on several previous reports $[2,13,14]$. An intravenous glucose tolerance test (IVGTT) was chosen as a convenient and appropriate method for testing the glucose-stimulated insulin response and capacity for blood glucose clearance [15]. The main advantages of an IVGTT is that it can reveal the loss of glucose tolerance at an early stage of metabolic syndrome and type 2 diabetes development by

*Corresponding author: Stefan G Pierzynowski, Department of Biology, Lund University, Solvegatan 35, SE 223 62, Lund, Sweden, Tel:+46709780202; E-mail: stefan.pierzynowski@biol.lu.se

Received April 25, 2016; Accepted June 19, 2016; Published June 27, 2016

Citation: Pierzynowski SG, Goncharova K, Woliński J, Prykhodko O, Weström B, et al. (2016) Enteral Pancreatic-like Enzymes of Microbial Origin affect Insulin Release during an Intravenous Glucose Tolerance Test. J Diabetes Metab 7: 681 doi:10.4172/2155-6156.1000681

Copyright: () 2016 Pierzynowski SG, et al. This is an open-access article distributed under the terms of the Creative Commons Attribution License, which permits unrestricted use, distribution, and reproduction in any medium, provided the original author and source are credited. 
Citation: Pierzynowski SG, Goncharova K, Woliński J, Prykhodko O, Weström B, et al. (2016) Enteral Pancreatic-like Enzymes of Microbial Origin affect Insulin Release during an Intravenous Glucose Tolerance Test. J Diabetes Metab 7: 681. doi:10.4172/2155-6156.1000681

Page 2 of 8

detecting lower blood glucose utilization. An IVGTT excludes the oral route of glucose delivery together with the associated enteral hormone secretion. Young healthy pigs were used as the experimental model because of their physiological similarity to humans, good reproducibility, and ability to be trained, which decreases stress under experimental conditions [16,17]. For those reasons, we studied the effects of supplementation of pancreatic-like enzymes of microbial origin alone, and in combination with AKG, on blood glucose tolerance and plasma insulin response during an IVGTT in young healthy pigs.

\section{What is the central question of this study?} IVGTT?

Do pancreatic-like enzymes influence glucose tolerance during an

\section{What is the main finding and its importance?}

Oral supplementation with $a$-amylase of microbial origin prior to an intravenous glucose tolerance test resulted in decreased insulin release with further increased insulin sensitivity while supplementation with proteinase decreased insulin sensitivity by increasing insulin release. The mechanism behind this finding is not understood, but pancreatic - like enzyme dietary supplementation may be considered as an alternative for improving blood glucose regulation under healthy, diabetic/obese conditions.

\section{Materials and Methods}

\section{Animals}

The study was approved by the Malmo/Lund Ethical Review Committee on Animal Experiments. The experiments were performed on 5 crossbred ((Yorkshire $\times$ Swedish Landrace $) \times$ Hampshire) pigs at an age of 7 weeks $(9.6 \pm 0.7 \mathrm{~kg})$. The pigs were housed individually in pens in the same stable at $20 \pm 2^{\circ} \mathrm{C}$ and with lights on from 7.0019.00. The pigs had free access to water via a drinking nipple and were fed a commercial pelleted pig feed (Vaxtill 320, Lantmännen, Sweden). In total, the feed was offered in an amount of $4 \%$ of the pigs body weight $(0.504 \mathrm{MJ} / \mathrm{kg} /$ day $)$ which was divided between the morning and afternoon meal. The pigs were accustomed to the experimental conditions for 1 week prior to commencement of the experiment in order to prevent stress during the experimental period.

In order to collect blood samples during the experiments, surgery was performed to implant a catheter into the anterior vena cava, via the external jugular vein. After an overnight fasting period the pigs were pre-medicated with azaperone (Stresnil ${ }^{\circledR}$, Janssen Pharmaceutica, Belgium, $2.2 \mathrm{mg} / \mathrm{kg}$, intramuscularly) and washed using surgical soap. The pigs were then anaesthetized via an inhalation mask with a 0.5 $1.5 \%$ air mixture of Fluothane ${ }^{\circledR}$ (Astra Läkemedel, Sodertälje, Sweden) in $\mathrm{O}_{2}$ as a carrier gas at approximately $0.5-1 \mathrm{~L} / \mathrm{min}$, using a closecircuit respiratory flow system (Komesaroff Medical Developments, Melbourne, Australia). Surgical anaesthesia was indicated by a lack of corneal reflex. Post-operative pain was prevented by administration of buprenorphine (Temgesic ${ }^{\mathbb{B}}$, Schering-Plough $A B, 0.01 \mathrm{mg} / \mathrm{kg}$, intramuscularly) for 1 day. Ampicillin (Doktacillin, Astra Läkemedel, Södertälje, Sweden) was administrated i.v. $(15 \mathrm{mg} / \mathrm{kg})$ and at the incision site (250-500 mg).

At the end of the experimental period, the pigs were euthanized by an i.v. injection of an overdose of pentobarbital sodium (Allfatal Vet. Omnidea, Stockholm, Sweden, $100 \mathrm{mg} / \mathrm{kg}$,) and post-mortem examinations were performed.

\section{Experiments and design}

Pancreatic-like enzymes of microbial origin (Proteinase P4032 from Aspergillus melleus; Amylase A9857 from Aspergillus oryzae; and Lipase 534641 from Burkholderia cepacia, all from Sigma-Aldrich) were tested separately, as a mixture and in combination with AKG, as oral supplements (A - $\alpha$-amylase; $\mathrm{P}$ - proteinase; $\mathrm{L}$ - lipase, $\mathrm{PAL}$ - mixture of proteinase+ amylase+ lipase, PA - mixure of proteinase+ amylase, $\mathrm{PL}$ - mixture of proteinase+ lipase; $\mathrm{AL}$ - mixture of amylase+ lipase; AKG - $\alpha$-ketoglutaric acid; +AKG - mixture of enzyme, or enzyme combination with $\alpha$-ketoglutaric acid). The dose of the enzymes per pig (3.37 $\mathrm{g}$ of $\alpha$-amylase, $100 \mathrm{mg}$ of proteinase and $100 \mathrm{mg}$ of microbial lipase), was chosen to match the corresponding enzymatic activities of 4 capsules of commercial pancrelipase (Creon 10,000, Abbott Healthcare Products Ltd, Southampton, United Kingdom) as used in a previous study in pigs [18-20].

The proteolytic activity was measured using casein as a substrate and with Folin's reagent detecting the released tyrosine. Amylolytic activity was analysed using ethylidene-pNP-G7 (4,6-ethylidene-p-nitrophenylalpha, D-maltoheptaoside) as the substrate, according to the manufacturer's instructions (Infinity Amylase Liquid Stable Reagent; Thermo Electron, Victoria, Australia). Lipase activity was analysed using 1,2-o-dilauryl-rac-glycero-3-glutaric acid (6'-ethylresorufin) ester as the substrate (Randox Laboratories, Crumlin Co. Antrim, Northern Ireland, United Kingdom), according to the manufacturer's instructions. The specific activity in $1 \mathrm{mg}$ of individual enzymes were measured at $37^{\circ} \mathrm{C}$ and compared with the activity of 1 pancrelipase capsule dissolved in PBS buffer ( $\mathrm{pH}$ 7.2).

The AKG supplement consisted of $50 \%$ of $\mathrm{Na}_{2}-\mathrm{AKG} \times 2 \mathrm{H}_{2} \mathrm{O}(0.144$ $\mathrm{g} / 1 \mathrm{~kg}$ body weight), and $50 \%$ of Ca-AKG ( $0.127 \mathrm{~g} / 1 \mathrm{~kg}$ body weight) which is equivalent to $1 \%$ of a single feed portion (equal to $0.02 \%$ of body weight). The dose of AKG was based on that used in previous publications involving porcine models $[21,22]$.

The lyophilized microbial enzymes, and the AKG salts were dissolved in $30 \mathrm{ml}$ of tap water and sweetened with saccharin (3 tablets of Hermesetas mini sweeteners, Valora Trade Denmark Food, Herlev, Denmark).

These enzyme solutions were administered orally using a syringe within 2 minutes after which the pigs received another $40 \mathrm{ml}$ of tap water to rinse the mouth and throat. As a control solution, $30 \mathrm{ml}$ of sweetened water, without enzymes or AKG, was administered. Control feedings were performed on 3 occasions during the experimental period and the average value of these was used since no significant differences between control data were seen. The experimental design is shown in Table 1.

\section{IVGTT}

The IVGTT was performed on the pigs following an overnight fast of about 20 hours. One hour prior to the glucose infusion, oral administration of the enzyme, enzyme $+\mathrm{AKG}$ or control solutions was performed. Glucose loading was carried out with a sterile $50 \%$ D-glucose solution $(0.5 \mathrm{~g} / \mathrm{kg}$ body weight $)$ infused via the venous catheter during 60 seconds. Immediately after this, the catheter was flushed with $5 \mathrm{ml}$ of $0.9 \%$ sterile saline solution. Blood samples were drawn from the jugular catheter at 1 minute before (time point 0 ), and at 5, 15, 30, 45, 60 and 120 minutes after the glucose infusion. Blood was collected into $5 \mathrm{ml}$ syringes containing EDTA $(0.20 \mathrm{mg})$ and a protease inhibitor, aprotinin (1000 kIU, Bayer, Leverkusen, Germany) and immediately cooled on ice. The blood was then centrifuged at 3000 
Citation: Pierzynowski SG, Goncharova K, Woliński J, Prykhodko O, Weström B, et al. (2016) Enteral Pancreatic-like Enzymes of Microbial Origin affect Insulin Release during an Intravenous Glucose Tolerance Test. J Diabetes Metab 7: 681. doi:10.4172/2155-6156.1000681

Page 3 of 8

\begin{tabular}{|c|c|c|c|c|c|c|}
\hline Pig Day & 1 & 3 & 5 & 7 & 9 & 11 \\
\hline 1 & Control & Amylase & AKG & Amylase+AKG & Control & Lipase \\
\hline II & Control & Amylase & AKG & Amylase+AKG & Control & Lipase \\
\hline III & Control & AKG & Amylase+AKG & Amylase & Control & Lipase \\
\hline IV & Control & AKG & Amylase+AKG & Amylase & Control & Lipase+AKG \\
\hline V & Control & Amylase+AKG & Amylase & AKG & Control & Lipase+AKG \\
\hline Pig Day & 13 & 15 & 17 & 19 & 21 & 23 \\
\hline 1 & Lipase+AKG & Proteinase & Proteinase+AKG & Control & PAL & $P A L+A K G$ \\
\hline II & Lipase+AKG & Proteinase & Proteinase+AKG & Control & PAL & $\mathrm{PAL}+\mathrm{AKG}$ \\
\hline III & Lipase+AKG & Proteinase & Proteinase+AKG & Control & PAL & $P A L+A K G$ \\
\hline IV & Lipase & Proteinase+AKG & Proteinase & Control & $P A L+A K G$ & PAL \\
\hline V & Lipase & Proteinase+AKG & Proteinase & Control & $P A L+A K G$ & PAL \\
\hline$P_{i g}^{\text {Day }}$ & 25 & 27 & 31 & 31 & 33 & 35 \\
\hline 1 & PA & $P A+A K G$ & $\mathrm{AL}$ & $A L+A K G$ & $\mathrm{PL}$ & PL+AKG \\
\hline II & PA & $P A+A K G$ & $\mathrm{AL}$ & $A L+A K G$ & $\mathrm{PL}$ & $P L+A K G$ \\
\hline III & PA & PA+AKG & $\mathrm{AL}$ & $A L+A K G$ & $\mathrm{PL}$ & PL+AKG \\
\hline IV & $\mathrm{PA}+\mathrm{AKG}$ & PA & $A L+A K G$ & $\mathrm{AL}$ & $\mathrm{PL}+\mathrm{AKG}$ & $\mathrm{PL}$ \\
\hline V & $P A+A K G$ & PA & $A L+A K G$ & $\mathrm{AL}$ & $\mathrm{PL}+\mathrm{AKG}$ & PL \\
\hline
\end{tabular}

Table 1: Experimental design. AKG - $\alpha$-ketoglutaric acid salt ( $50 \%$ of $\mathrm{Na}_{2}-\mathrm{AKG} * 2 \mathrm{H}_{2} \mathrm{O}+50 \%$ of $\left.\mathrm{Ca}-\mathrm{AKG}\right), \mathrm{PAL}-$ pancreatic-like enzymes mixture, $\mathrm{PA}-\mathrm{proteinase}+\mathrm{amylase}$ $\mathrm{PL}$ - proteinase+lipase; $\mathrm{AL}$ - amylase+lipase.

$\times g$ for 15 min at $4^{\circ} \mathrm{C}$ and plasma was separated and stored at $-20^{\circ} \mathrm{C}$ until analyses.

\section{Analysis of blood glucose and plasma insulin and C-peptide}

Glucose was measured in the fresh blood samples using a glucosemeter with test strips (Accu-Chek ${ }^{\circledR}$ Aviva, Roche Diagnostics, Mannheim, Germany). Plasma insulin and C-peptide levels were measured using porcine insulin or C-peptide ELISA kits, respectively (Mercodia, Uppsala, Sweden), mainly according to manufacturer's protocol, but with an increased sample volume $(50 \mu \mathrm{L})$ and an additional standard point at the lower end of the standard curve, obtaining a lower detection limit of $0.2 \mathrm{pmol} / \mathrm{L}$ for insulin and $2 \mathrm{pmol} / \mathrm{L}$ for C-peptide.

\section{Statistical analysis and calculations}

The total area under the curve (AUC) was calculated for the postinfusion glucose, insulin and C-peptide curves using the trapezoidal rule.

Insulin sensitivity was calculated as a surrogate index (S2), using the classic glucose disappearance rate $(k)$ related to released insulin concentration during $0-30$ minutes, $30^{*} \mathrm{k} /{ }_{0-30} \mathrm{AUC}_{\text {insulin }}$. The glucose disappearance rate is the negative slope of the linear regression of the logarithm of glucose, in a 25-min interval from 5 to $30 \mathrm{~min}$ $\left(k=\frac{\mathrm{Ln} 1-\mathrm{Ln} 2}{\mathrm{~T} 2-\mathrm{T} 1}\right)$. The incremental area under the curve of insulin concentration from 0 to $30 \mathrm{~min}$ was calculated using the trapezoidal rule $\left({ }_{0-30} \mathrm{AUC}_{\text {insulin }}\right)$. The units of the index are $1 / \mathrm{min}^{*} \mathrm{pM}$ [15].

Statistical analysis was performed using Prism, version 6 (GraphPad Software, Inc, San Diego, CA, USA) and R (v. 3.0.1) programming environment. The differences for the AUC and S2 between treatments and control values were determined using a one-way Anova with a Dunnett's multiple comparison post-hoc test. Summarized effect of enzyme action presented as aggregated data obtained from supplements containing specific enzyme in comparison to supplements not containing enzyme. We used the repeated measures, mixed-effect model to compare the enzyme presence as a fixed effect, with pig and supplement as random effects. A p-value of $<0.05$ was considered to be statistically significant while a $\mathrm{p} \leq 0.1$ was considered a tendency.

\section{Results}

\section{Effect of different supplements on glucose utilization during the IVGTT}

In general, glucose utilization during the IVGTT followed a similar pattern on all experimental days and blood glucose levels returned to baseline levels 30 minutes following the glucose infusion (Table 2). $\mathrm{AUC}_{\text {glucose }}$ represents the total glucose utilization during the IVGTT. Oral administration of the supplements tested $1 \mathrm{~h}$ prior to the IVGTT had no significant influence on total blood glucose utilization (Table 3 , AUC $_{\text {glucose }}$, Figures 1-3).

\section{Effect of different supplements on insulin response and insulin sensitivity during the IVGTT}

Plasma insulin levels peaked at 5 and 15 minutes following the glucose infusion and returned to baseline levels 30 minutes following the glucose infusion (Table 2). Analysis of plasma C-peptide levels was performed only to confirm the insulin response after $\alpha$-amylase supplementation (Table 2). The plasma C-peptide levels following administration of $\alpha$-amylase were significantly lower 30 minutes following glucose infusion, than those observed following administration of the control solution $\left(\mathrm{AUC}_{\mathrm{C} \text {-peptide }} 3.3 \pm 0.3\right.$ and $4.4 \pm$ 0.1 , with $\mathrm{p}=0.01$ ).

The total insulin response observed during the IVGTT was reflected in the $\mathrm{AUC}_{\text {insulin }}$ (Table 3 ) and $\alpha$-amylase supplementation resulted in

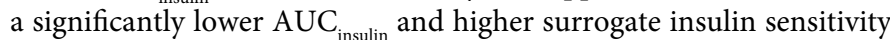
index S2 compared to that observed following administration of the control solution $(p=0.03)$. Tendency to lower $A_{U C} C_{\text {insulin }}$ was also found after supplementation of amylase together with $A K G(A+A K G$, $\mathrm{p}=0.1$ ). Oral administration of a combined supplement, containing proteinase+lipase $+\mathrm{AKG}(\mathrm{PL}+\mathrm{AKG})$ resulted in a significantly higher insulin response $(\mathrm{p}=0.002)$. The mixture of proteinase+lipase $(\mathrm{PL})$ had a tendency to increase the insulin response $(p=0.09)$. 
Citation: Pierzynowski SG, Goncharova K, Woliński J, Prykhodko O, Weström B, et al. (2016) Enteral Pancreatic-like Enzymes of Microbial Origin affect Insulin Release during an Intravenous Glucose Tolerance Test. J Diabetes Metab 7: 681. doi:10.4172/2155-6156.1000681

Page 4 of 8

\begin{tabular}{|c|c|c|c|c|c|c|c|}
\hline \multirow{3}{*}{ Supplement } & \multicolumn{7}{|c|}{ IVGTT } \\
\hline & Fasting baseline & \multirow[t]{2}{*}{$0^{\prime}$} & \multirow[t]{2}{*}{5} & $15^{\prime}$ & $30^{\prime}$ & $60^{\prime}$ & $120^{\prime}$ \\
\hline & \multicolumn{5}{|c|}{ Glucose, $\mathrm{mmol} / \mathrm{L}$} & & \\
\hline Control & $4.5 \pm 0.1$ & $4.1 \pm 0.2$ & $15.9 \pm 0.2$ & $7.4 \pm 0.1$ & $2.9 \pm 0.1$ & $3.1 \pm 0.1$ & $3.9 \pm 0.1$ \\
\hline PAL & $4.7 \pm 0.2$ & $4.2 \pm 0.2$ & $15.6 \pm 0.2$ & $7.5 \pm 0.1$ & $2.3 \pm 0.3$ & $3.3 \pm 0.2$ & $4.0 \pm 0.3$ \\
\hline $\mathrm{P}$ & $4.6 \pm 0.3$ & $4.4 \pm 0.2$ & $16.0 \pm 0.6$ & $7.5 \pm 0.3$ & $2.8 \pm 0.3$ & $3.2 \pm 0.3$ & $4.1 \pm 0.4$ \\
\hline A & $4.3 \pm 0.1$ & $3.1 \pm 0.2$ & $13.9 \pm 0.2$ & $8.2 \pm 0.4$ & $3.1 \pm 0.2$ & $2.9 \pm 0.1$ & $3.9 \pm 0.3$ \\
\hline L & $4.6 \pm 0.2$ & $4.2 \pm 0.2$ & $16.4 \pm 0.4$ & $9.0 \pm 0.4$ & $3.5 \pm 0.3$ & $2.9 \pm 0.2$ & $3.8 \pm 0.3$ \\
\hline PA & $4.7 \pm 0.1$ & $4.4 \pm 0.1$ & $16.8 \pm 0.1$ & $7.1 \pm 0.4$ & $2.1 \pm 0.1$ & $3.2 \pm 0.2$ & $3.9 \pm 0.1$ \\
\hline $\mathrm{PL}$ & $4.8 \pm 0.2$ & $4.4 \pm 0.1$ & $17.3 \pm 0.3$ & $7.7 \pm 0.4$ & $2.7 \pm 0.3$ & $2.8 \pm 0.2$ & $3.5 \pm 0.3$ \\
\hline $\mathrm{AL}$ & $4.5 \pm 0.3$ & $4.8 \pm 0.2$ & $16.0 \pm 0.5$ & $7.0 \pm 0.3$ & $2.1 \pm 0.2$ & $3.0 \pm 0.2$ & $3.8 \pm 0.3$ \\
\hline AKG & $4.3 \pm 0.2$ & $4.2 \pm 0.2$ & $16.4 \pm 0.9$ & $9.7 \pm 0.8$ & $4.4 \pm 1.0$ & $2.8 \pm 0.3$ & $3.9 \pm 0.2$ \\
\hline$P A L+A K G$ & $4.5 \pm 0.3$ & $4.3 \pm 0.5$ & $16.1 \pm 0.5$ & $7.5 \pm 0.3$ & $2.1 \pm 0.2$ & $3.3 \pm 0.2$ & $3.9 \pm 0.2$ \\
\hline $\mathrm{P}+\mathrm{AKG}$ & $4.4 \pm 0.2$ & $4.3 \pm 0.1$ & $16.1 \pm 0.8$ & $7.6 \pm 0.2$ & $3.2 \pm 0.1$ & $2.8 \pm 0.2$ & $3.6 \pm 0.4$ \\
\hline$A+A K G$ & $4.3 \pm 0.1$ & $3.6 \pm 0.4$ & $15.2 \pm 0.4$ & $8.4 \pm 0.7$ & $3.4 \pm 0.6$ & $3.2 \pm 0.2$ & $4.2 \pm 0.1$ \\
\hline$L+A K G$ & $4.8 \pm 0.1$ & $4.4 \pm 0.1$ & $15.3 \pm 0.4$ & $7.8 \pm 0.2$ & $2.9 \pm 0.2$ & $2.8 \pm 0.1$ & $3.9 \pm 0.1$ \\
\hline$P A+A K G$ & $4.8 \pm 0.2$ & $4.7 \pm 0.2$ & $17.4 \pm 1.1$ & $7.5 \pm 0.3$ & $2.1 \pm 0.1$ & $3.3 \pm 0.3$ & $4.0 \pm 0.3$ \\
\hline$P L+A K G$ & $4.8 \pm 0.1$ & $4.6 \pm 0.1$ & $17.2 \pm 0.5$ & $8.3 \pm 0.3$ & $2.8 \pm 0.3$ & $2.9 \pm 0.2$ & $3.5 \pm 0.1$ \\
\hline$A L+A K G$ & $4.7 \pm 0.2$ & $4.1 \pm 0.3$ & $16.1 \pm 0.9$ & $7.0 \pm 0.6$ & $2.2 \pm 0.3$ & $3.1 \pm 0.1$ & $4.0 \pm 0.3$ \\
\hline & & & & Insulin, pmol/L & & & \\
\hline Control & $1.3 \pm 0.2$ & $1.7 \pm 0.2$ & $34.5 \pm 2.9$ & $37.3 \pm 0.8$ & $4.0 \pm 0.1$ & $1.0 \pm 0.1$ & $0.6 \pm 0.1$ \\
\hline PAL & $2.1 \pm 0.8$ & $0.8 \pm 0.3$ & $29.6 \pm 2.4$ & $37.5 \pm 5.4$ & $3.2 \pm 0.3$ & $0.8 \pm 0.1$ & $0.7 \pm 0.2$ \\
\hline $\mathrm{P}$ & $1.3 \pm 0.2$ & $1.2 \pm 0.1$ & $33.0 \pm 5.6$ & $35.2 \pm 3.7$ & $4.0 \pm 0.4$ & $0.9 \pm 0.1$ & $2.0 \pm 0.9$ \\
\hline A & $2.9 \pm 0.6$ & $1.1 \pm 0.2$ & $15.8 \pm 2.6$ & $24.1 \pm 3.8$ & $3.1 \pm 0.4$ & $1.1 \pm 0.2$ & $1.4 \pm 0.3$ \\
\hline L & $1.8 \pm 0.4$ & $1.3 \pm 0.3$ & $26.0 \pm 3.0$ & $34.7 \pm 2.3$ & $4.7 \pm 0.9$ & $0.9 \pm 0.1$ & $0.9 \pm 0.1$ \\
\hline PA & $1.9 \pm 0.7$ & $1.3 \pm 0.4$ & $30.9 \pm 4.0$ & $44.1 \pm 2.8$ & $3.4 \pm 0.2$ & $0.6 \pm 0.0$ & $0.5 \pm 0.1$ \\
\hline $\mathrm{PL}$ & $2.0 \pm 0.4$ & $1.8 \pm 0.1$ & $42.3 \pm 3.1$ & $48.5 \pm 5.4$ & $5.3 \pm 0.4$ & $1.5 \pm 0.2$ & $1.4 \pm 0.3$ \\
\hline $\mathrm{AL}$ & $1.5 \pm 0.4$ & $1.6 \pm 0.5$ & $45.4 \pm 6.1$ & $35.2 \pm 5.9$ & $4.1 \pm 0.3$ & $1.0 \pm 0.1$ & $0.9 \pm 0.3$ \\
\hline AKG & $2.9 \pm 0.8$ & $1.6 \pm 0.4$ & $33.3 \pm 4.8$ & $37.5 \pm 5.3$ & $4.8 \pm 0.6$ & $0.9 \pm 0.1$ & $0.7 \pm 0.1$ \\
\hline $\mathrm{PAL}+\mathrm{AKG}$ & $1.6 \pm 0.6$ & $0.6 \pm 0.1$ & $28.5 \pm 3.8$ & $37.7 \pm 4.5$ & $3.0 \pm 0.3$ & $0.6 \pm 0.0$ & $1.0 \pm 0.3$ \\
\hline $\mathrm{P}+\mathrm{AKG}$ & $1.5 \pm 0.4$ & $1.2 \pm 0.4$ & $37.1 \pm 4.7$ & $43.3 \pm 5.7$ & $4.3 \pm 0.3$ & $0.8 \pm 0.1$ & $0.8 \pm 0.2$ \\
\hline$A+A K G$ & $1.3 \pm 0.1$ & $1.7 \pm 0.5$ & $20.4 \pm 3.5$ & $27.9 \pm 2.2$ & $2.9 \pm 0.5$ & $1.0 \pm 0.2$ & $0.9 \pm 0.2$ \\
\hline$L+A K G$ & $1.4 \pm 0.3$ & $1.3 \pm 0.2$ & $32.0 \pm 4.3$ & $35.3 \pm 6.0$ & $4.1 \pm 0.6$ & $0.7 \pm 0.1$ & $1.2 \pm 0.4$ \\
\hline $\mathrm{PA}+\mathrm{AKG}$ & $1.0 \pm 0.4$ & $1.9 \pm 0.9$ & $34.3 \pm 5.5$ & $42.6 \pm 3.7$ & $3.6 \pm 0.4$ & $0.6 \pm 0.1$ & $0.7 \pm 0.2$ \\
\hline$P L+A K G$ & $1.3 \pm 0.2$ & $1.8 \pm 0.4$ & $45.5 \pm 4.8$ & $54.5 \pm 6.6$ & $5.3 \pm 0.6$ & $3.1 \pm 1.9$ & $1.1 \pm 0.2$ \\
\hline$A L+A K G$ & $1.3 \pm 0.2$ & $2.4 \pm 1.0$ & $33.9 \pm 4.6$ & $31.3 \pm 5.6$ & $3.6 \pm 0.0$ & $1.1 \pm 0.2$ & $1.2 \pm 0.3$ \\
\hline & & & & C-peptide, pmol/ & & & \\
\hline Control & $10.3 \pm 2.2$ & $175.7 \pm 11.3$ & $212.3 \pm 6.9$ & $51.0 \pm 4.6$ & V/M & $\mathrm{N} / \mathrm{M}$ & $\mathrm{N} / \mathrm{M}$ \\
\hline Amylase & $4.6 \pm 1.0$ & $106.0 \pm 12.0$ & $174.8 \pm 17.1$ & $37.3 \pm 5$ & V/M & $\mathrm{N} / \mathrm{M}$ & $\mathrm{N} / \mathrm{M}$ \\
\hline
\end{tabular}

Table 2: Blood glucose, plasma insulin and C-peptide levels during an IVGTT in pigs 1 hour after oral administration of different supplements. Control - water solution; A -amylase; $\mathrm{P}$-proteinase; $\mathrm{L}$-lipase, $\mathrm{PAL}$ - mixture of proteinase+amylase+lipase, $\mathrm{PA}$ - mixure of proteinase+amylase, $\mathrm{PL}-\mathrm{mixture}$ of proteinase+lipase; $\mathrm{AL}$ - mixture of amylase+lipase; AKG - $\alpha$-ketoglutaric acid;+AKG - mixture of enzyme, or enzymes combination with $\alpha$-ketoglutaric acid. The results are means \pm SEM, ( $n=5$ ). N/M- not measured.

The complex enzyme effect on oral feeding insulin response, calculated as an average from the data obtained for different supplements, contained the reviewed enzymes. As a result, the presence of proteinase in the supplements led to a higher AUC and lower insulin sensitivity index S2 during the IVGTT (Figures 1 and 4). The presence of microbial $\alpha$-amylase resulted in a lower total insulin response and increased insulin sensitivity during the IVGTT, compared to that obtained following administration of the supplements which did not contain amylase $\left(\mathrm{AUC}_{\text {glucose }}\right.$, S2, Figure 2). Comparison of proteinase and amylase administrations showed contrary effects of both enzymes on insulin sensitivity (S2, Figure 4). Lipase presence had a tendency to increase the total insulin response with no effect on insulin sensitivity during the IVGTT (S2, Figure 3). AKG addition to enzyme supplementation had no effect on the parameters investigated.

\section{Discussion}

Blood glucose and insulin control is dependent on a variety of factors, and can be influenced at various different stages [6]. The recognition of compounds, which would trigger nutrient assimilation, is important for the prevention of metabolic dysregulation and for the treatment of different forms of diabetes. Previous studies have found that pancreatic enzyme supplementation can have a measurable influence on insulin efficiency [9]. Moreover, a considerable number of publications have reported the development of metabolic syndrome in humans with a lower activity of pancreatic amylase in their plasma [23-26]. In the majority of cases, lower plasma pancreatic amylase activity also represents a reduced supply of pancreatic amylase to the duodenum. In addition, type $3 \mathrm{c}$ diabetes is exocrine pancreas-related, 
Citation: Pierzynowski SG, Goncharova K, Woliński J, Prykhodko O, Weström B, et al. (2016) Enteral Pancreatic-like Enzymes of Microbial Origin affect Insulin Release during an Intravenous Glucose Tolerance Test. J Diabetes Metab 7: 681. doi:10.4172/2155-6156.1000681

Page 5 of 8

\begin{tabular}{|c|c|c|c|}
\hline Supplement & AUC glucose $\mathrm{mmol} / \mathrm{L} / 120 \mathrm{~min}$ & AUC insulin $\mathrm{pmol} / \mathrm{L} / 120 \mathrm{~min}$ & S2, $\mathrm{pmol} / \mathrm{L} / 30 \mathrm{~min}$ \\
\hline Control (Water) & $544 \pm 9$ & $881 \pm 17$ & $0.27 \pm 0.01$ \\
\hline PAL & $542 \pm 15$ & $814 \pm 90$ & $0.34 \pm 0.04$ \\
\hline$P$ & $558 \pm 27$ & $882 \pm 84$ & $0.31 \pm 0.04$ \\
\hline A & $531 \pm 24$ & $581 \pm 80^{*}$ & $0.43 \pm 0.05^{*}$ \\
\hline $\mathrm{L}$ & $569 \pm 16$ & $804 \pm 68$ & $0.29 \pm 0.04$ \\
\hline PA & $546 \pm 22$ & $905 \pm 68$ & $0.32 \pm 0.03$ \\
\hline PL & $543 \pm 20$ & $1157 \pm 86 \sim$ & $0.25 \pm 0.03$ \\
\hline $\mathrm{AL}$ & $541 \pm 26$ & $949 \pm 89$ & $0.32 \pm 0.05$ \\
\hline AKG & $597 \pm 40$ & $892 \pm 92$ & $0.22 \pm 0.01$ \\
\hline $\mathrm{PAL}+\mathrm{AKG}$ & $535 \pm 12$ & $812 \pm 60$ & $0.36 \pm 0.02 \sim$ \\
\hline$P+A K G$ & $530 \pm 19$ & $976 \pm 119$ & $0.25 \pm 0.04$ \\
\hline$A+A K G$ & $572 \pm 30$ & $642 \pm 58 \sim$ & $0.37 \pm 0.05 \sim$ \\
\hline$L+A K G$ & $534 \pm 9$ & $844 \pm 109$ & $0.32 \pm 0.06$ \\
\hline $\mathrm{PA}+\mathrm{AKG}$ & $560 \pm 31$ & $938 \pm 100$ & $0.32 \pm 0.03$ \\
\hline$P L+A K G$ & $546 \pm 13$ & $1316 \pm 115^{\star *}$ & $0.22 \pm 0.03$ \\
\hline$A L+A K G$ & $559 \pm 23$ & $818 \pm 61$ & $0.40 \pm 0.05 \sim$ \\
\hline
\end{tabular}

Table 3: Blood glucose utilization, plasma insulin response during IVGTT and insulin sensitivity index S2 in pigs 1 hour after oral administration of different supplements. Control - water solution; A -amylase; P - proteinase; $L$ - lipase, PAL - mixture of proteinase+amylase+lipase, $P A$ - mixure of proteinase+amylase, PL - mixture of proteinase+lipase; $A L$ - mixture of amylase+lipase; AKG - a-ketoglutaric acid; +AKG - mixture of enzyme, or enzymes combination with $\alpha$-ketoglutaric acid. The results are means \pm SEM, $(n=5)$. *indicate significant difference, $p<0.05,{ }^{* *} p=0.001$ as compared to the Control value.
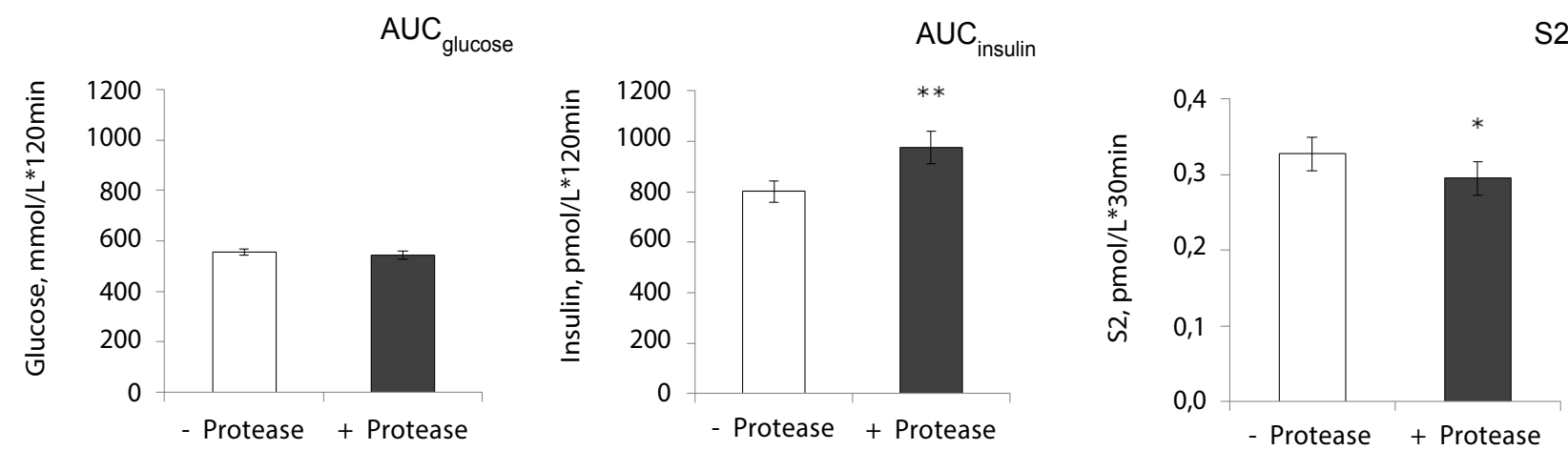

Figure 1: Effect of oral proteinase supplementation $1 \mathrm{~h}$ prior to IVGTT on blood glucose utilisation (AUC glucose ), insulin response (AUC insulin ) and insulin sensitivity index S2. Data shown as two merged data sets of supplements containing proteinase and those that do not contain proteinase. The results are means \pm SEM, ( $=5$ ) **indicates $p=0.008,{ }^{*} p<0.03$. -Proteinase: Control; AKG; $A ; L ; A L ; A+A K G ; L+A K G ; A L+A K G$. +Proteinase: $P$; $P+A K G ; P A ; P L ; P A L ; P A+A K G ; P L+A K G$; $P A L+A K G$. $A$ - $\alpha$-amylase; $P$ - proteinase; $L$ - lipase, AKG - $\alpha$-ketoglutaric acid.

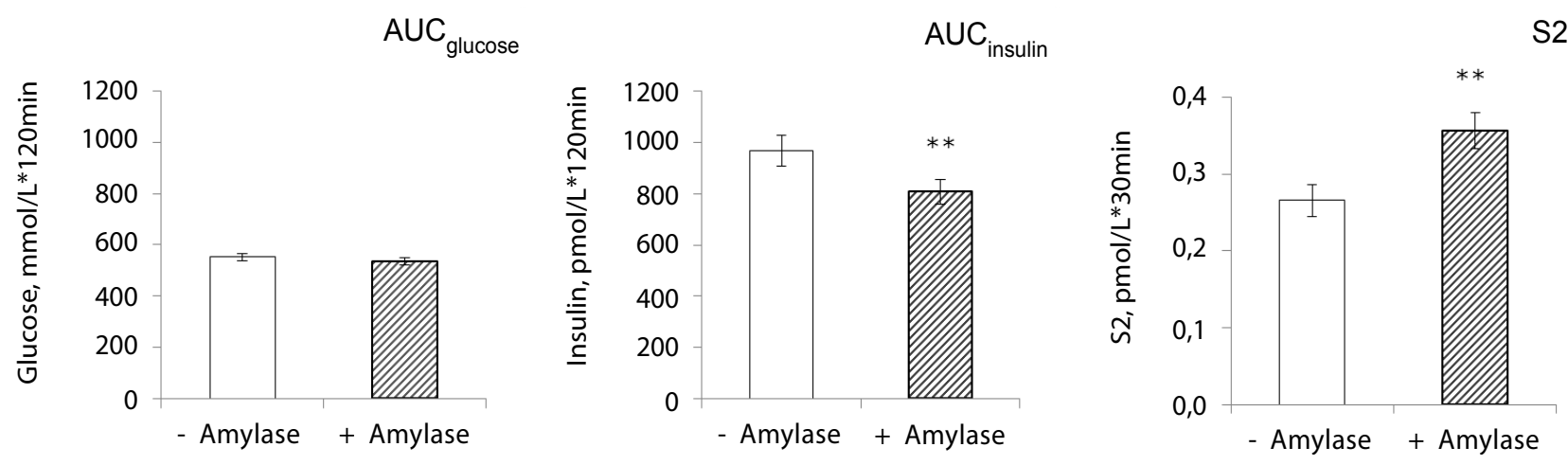

Figure 2: Effect of oral amylase supplementation $1 \mathrm{~h}$ prior to IVGTT on blood glucose utilisation (AUC glucose ), insulin response (AUC $\mathrm{C}_{\text {insulin }}$ ) and insulin sensitivity index S2. Data shown as two merged data sets of supplements containing amylase and those that do not contain amylase. The results are means $\pm S E M$, ( $n=5)$. **indicate significant difference, $p \leq$ 0.002. -Amylase: Control; AKG; P; L; PL; P+AKG; L+AKG; PL+AKG. +Amylase: A; A+AKG; PA; AL; PAL; PA+AKG; AL+AKG; PAL+AKG. $A$ - $\alpha$-amylase; $P$ - proteinase; $L$ - lipase, AKG - $\alpha$-ketoglutaric acid. 

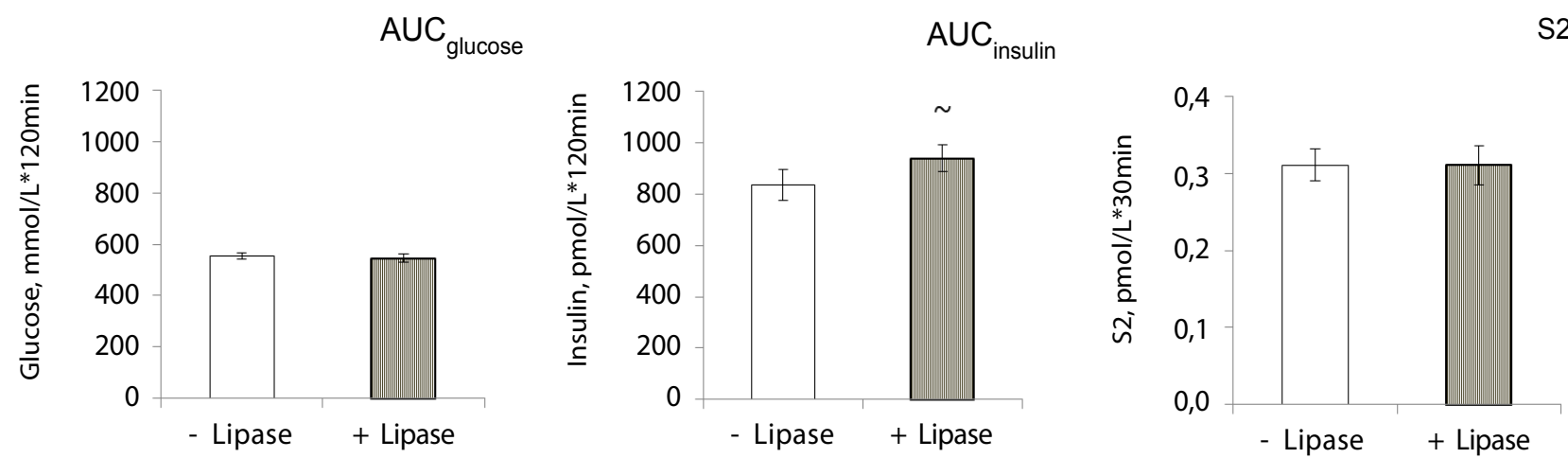

Figure 3: Effect of oral lipase supplementation $1 \mathrm{~h}$ prior to IVGTT on blood glucose utilisation (AUC ${ }_{\text {ouse }}$ ), insulin response (AUC ${ }_{\text {insuin }}$ ) and insulin sensitivity index S2 Data shown as two merged data sets of supplements containing lipase and those that do not contain lipase. The results are means \pm SEM, ( $n=5)$, with $\sim$ indicates $p=$

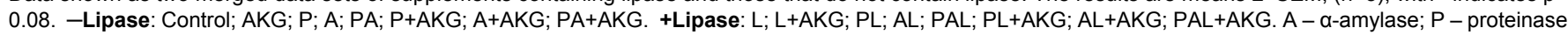
$\mathrm{L}$ - lipase, AKG - $\alpha$-ketoglutaric acid.
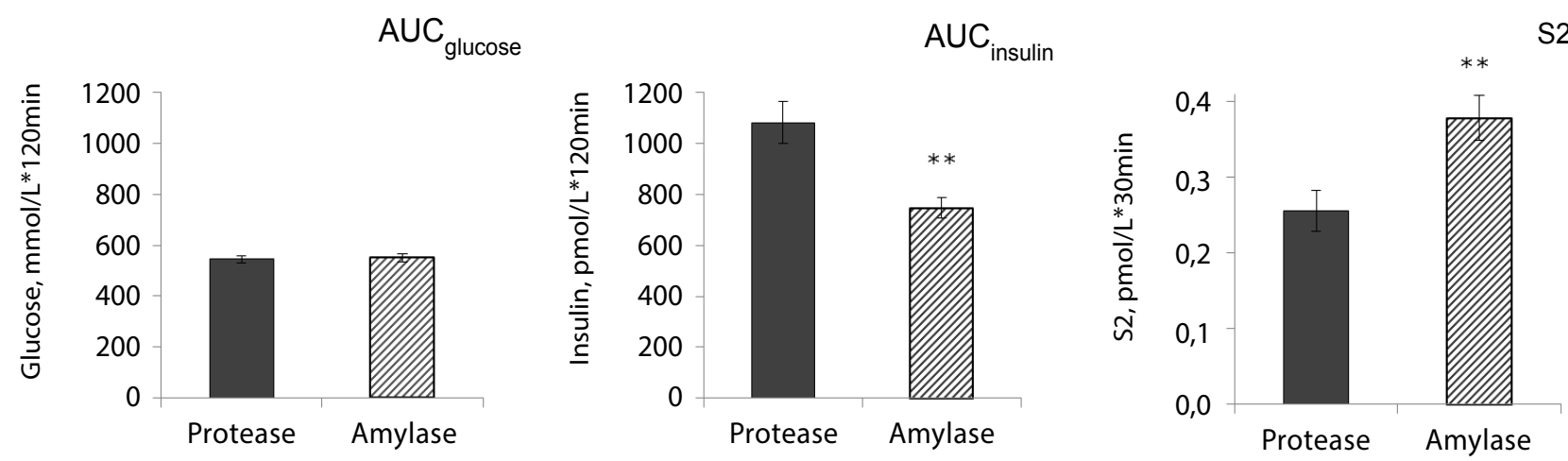

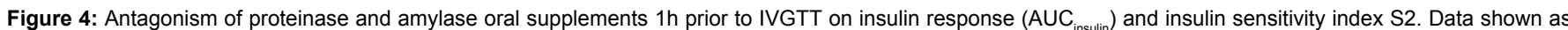
two merged data sets of supplements containing proteinase or amylase. The results are means $\pm S E M,(n=5)$. ${ }^{* *}$ indicate significant difference with $p \leq 0.005$. Protease P; PL, P+AKG; PL+AKG. Amylase: A; AL; A+AKG; AL+AKG. A - $\alpha$-amylase; P - proteinase; $L$ - lipase, AKG - $\alpha$-ketoglutaric acid.

which has also been confirmed by our lab, using a pig model [3]. In order to understand the purpose of the current study, as well as our hypothesis, one should consider that pancreatic enzymes are not only responsible for digestion, but also exhibit a positive influence on the luminal intestinal mucosa $[27,28]$.

In the present study we investigated the effects of oral administration of the main digestive components usually found within pancreatic juice (proteinase, amylase and lipase), on blood glucose and plasma insulin levels during an IVGTT, in order to validate our assumptions. In addition, the proteinase, amylase, and lipase of microbial origin are actually tested and used as alternatives to pancreatic enzymes of porcine origin (pancrelipase Creon ${ }^{\circledR}$ ) to treat pancreatic insufficiency [29].

Lipase administration in comparison to that of proteinase and amylase was found to have no influence in altering the insulin response. The ability of microbial proteinase to influence insulin augmentation requires additional investigation. This influence of microbial-derived proteinase could be due to the different substrate-specific activity with porcine trypsin (the main component of pancreatic juice) and different electrophoretic separations upon charge (data not shown). It was shown, that different proteases vary in cleavage sites on the proteaseactivated receptors (PAR) [30]. In addition, in experiments using EPI pigs, no increases in insulin response were detected following oral administration of a commercial mixture of pancreatic digestive enzymes [3]. The ability of proteinase to attenuate insulin sensitivity is perhaps related to its ability to potentiate inflammation [31]. The opposed results obtained following administration of proteinase and amylase reveal difference in enzyme action. Oral administration of microbial amylase alone, resulted in a reduced requirement for insulin in response to an intravenous glucose infusion, compared to that observed after administration of the control solution. The mixture of microbial $\alpha$-amylase together with lipase, proteinase and AKG, slightly deteriorated the impact of amylase on insulin release. However, a significantly decreased level of required insulin as an effect of oral amylase administration prior to IVGTT was detected in merged data sets.

Fungal amylase has sequences homologous to that of porcine and human amylases in its enzymatically functional regions [32]. The microbial $\alpha$-amylase used in the present study has been shown to remain active in the duodenum for as long as $1 \mathrm{~h}$ after oral administration Considerable degradation of the microbial $\alpha$-amylase is observed within the ileum of pigs with exocrine pancreatic insufficiency following oral administration of the microbial $\alpha$-amylase, together with proteinase and lipase in the form of pills [33]. However, healthy animals such as those used in the present study, retain the high proteolytic activity of their endogenous trypsin and other endo- and exopeptidases, which also implies a possible higher rate of proteinase activity, which may in turn affect the action of amylase. We are also not excluding the role 
Citation: Pierzynowski SG, Goncharova K, Woliński J, Prykhodko O, Weström B, et al. (2016) Enteral Pancreatic-like Enzymes of Microbial Origin affect Insulin Release during an Intravenous Glucose Tolerance Test. J Diabetes Metab 7: 681. doi:10.4172/2155-6156.1000681

Page 7 of 8

of peptides possibly derived following the digestion of $\alpha$-amylase or that of other enzymes through the action of endo- and exo-peptidases which are present in the gut lumen.

The effect of oral $\alpha$-amylase administration on lowering the insulin response was verified by the lower C-peptide levels. We should point out that we recognize the amelioration of the insulin sensitivity together with its lower release and possible attenuated insulin resistance (what is the clue for obesity, diabetes type II and metabolic syndrome) by dietary $a$-amylase as primary finding of our study. It has been postulated that results obtained can suggest that amylase food supplementation facilitates/promotes enterocyte glucose uptake from the blood. Insulin sensitivity index S2, which has been proposed to be relevant for pigs as an accurate representative insulin sensitivity index based on the IVGTT [15] was also highest following amylase administration.

Based on current results we can speculate, that pancreatic $a$-amylase, by interacting with the luminal epithelial cells, increases glucose consumption by enterocytes from the blood via insulin independent GLUT2 transporters on their basolateral side. Other mechanisms of $\alpha$-amylase action are not excluded e.g., via peptides appearing after the digestion of $a$-amylase by trypsin or other proteinases. The phenomenon of blood glucose regulation by amylase is probably of importance during the early stages of development in neonates, who produce quite a high amount of pancreatic amylase as they are being nursed exclusively by mother's milk. The presence of pancreatic amylase in the gut lumen during the suckling period is unclear since there is no substrate in the milk for $\alpha$-amylase to act on during that time [34]. Thus, maybe the regulation of glucose is the primary duty of pancreatic $\alpha$-amylase in neonates, taking into account the well-known fact that plasma insulin levels in neonatal pigs are essentially [34].

It has been shown that the enteral application of pancreatic enzymes $\left(\mathrm{Creon}^{\circledR}\right)$ never leads to increased levels of the corresponding enzymes in the blood, suggesting that no enzymes are absorbed from the lumen [18]. Also, to our knowledge, no connection between digestive enzyme activity in the gut and $\beta$-cell function has been reported. Moreover, in previous experiments on young pigs with induced exocrine pancreatic insufficiency, blood glucose clearance without reinforced insulin release was observed during an IVGTT, following pancrelipase feeding [3]. So, we are inclined to link any changes in blood parameters with the enzyme's influences on intestinal cells and their function.

Based on our previous research, AKG could also have an indirect influence on the parameters studied, due to its positive effect on the intestinal epithelium $[22,35]$. It was found that AKG, as well as digestive enzymes, interacts with enterocytes and is involved in amino acid biosynthesis, offering advantages in a catabolic state and thus may also affect the rate of gluconeogenesis in mucosa cells [2,21,34,36-38]. On the other hand, AKG in enterocytes undergoes amination and appears in the plasma as glutamate [36] which may stimulate insulin exocytosis from $\beta$-cells in response to glucose stimulation [39]. However, the oral supplementation of AKG in the amount used in our studies seemed not to be involved in the regulation of blood glucose utilization and insulin sensitivity.

In conclusion, the experiment shows that oral administration of microbial $\alpha$-amylase $1 \mathrm{~h}$ prior to the IVGTT can have a significant influence on the release of insulin required for glucose clearance in growing healthy pigs. The results suggest a para-digestive, insulinlike anabolic action of amylase on glucose utilization, which occurs via some unidentified mechanism in response to the presence of $a$-amylase in gut lumen. Microbial proteinase as opposed to amylase attenuated insulin sensitivity increasing its release, whereas lipase had no significant effect. Thus, $a$-amylase, can be suggested as the most important component of pancreatic juice, which, acting from the gut, regulates blood glucose utilization in an insulin independent manner, and in that way postpones the development of glucose intolerance. Obtained data point out the necessity for further investigations highlighting role of amylase and proteinase in post-prandial glucose utilization.

\section{Author Contributions}

All the work was done in the laboratories of the Department of Biology at Lund University (Sweden). S.G.P., L.L. conception and design of research; L.L. and S.G.P. performed experiments; L.L. analyzed data; S.G.P., L.L., K.G., J.W., O.P., and B.W. interpreted results of experiments; L.L. prepared and drafted manuscript S.G.P., L. L., K.G., J.W., O.P., and B.W. edited and revised manuscript; all authors gave approval for the final version of the manuscript to be published.

\section{References}

1. Bays HE (2004) Current and investigational antiobesity agents and obesity therapeutic treatment targets. Obes Res 12: 1197-1211.

2. Lambert BD, Filip R, Stoll B, Junghans $P$, Derno M, et al. (2006) First-pass metabolism limits the intestinal absorption of enteral alpha-ketoglutarate in young pigs. J Nutr 136: 2779-2784

3. Lozinska L, Weström B, Prykhodko O, Lindqvist A, Wierup N, et al. (2016) Decreased insulin secretion and glucose clearance in exocrine pancreasinsufficient pigs. Exp Physiol 101: 100-112.

4. McDougall GJ, Stewart D (2005) The inhibitory effects of berry polyphenols on digestive enzymes. Biofactors 23: 189-195

5. Creutzfeldt W (2000) The entero-insular axis in type 2 diabetes--incretins as therapeutic agents. Experimental and clinical endocrinology \& diabetes: officia journal, German Society of Endocrinology. [and] German Diabetes Association 109: S288-S303.

6. Bilous R, Donnelly R (2010) Handbook of diabetes. Wiley. com

7. Knop FK, Vilsbøll T, Larsen S, Højberg PV, Vølund A, et al. (2007) Increased postprandial responses of GLP-1 and GIP in patients with chronic pancreatitis and steatorrhea following pancreatic enzyme substitution. Am J Physio Endocrinol Metab 292: E324-330.

8. Ewald N, Hardt PD (2013) Diagnosis and treatment of diabetes mellitus in chronic pancreatitis. World J Gastroenterol 19: 7276-7281.

9. Mohan V, Poongothai S, Pitchumoni C (1998) Oral pancreatic enzyme therapy in the control of diabetes mellitus in tropical calculous pancreatitis. International journal of pancreatology 24: 19-22.

10. Glasbrenner B, Malfertheiner P, Kerner W, Scherbaum WA, Ditschuneit H (1990) Effect of pancreatin on diabetes mellitus in chronic pancreatitis. Z Gastroenterol 28: 275-279.

11. O'Keefe SJ, Cariem AK, Levy M (2001) The exacerbation of pancreatic endocrine dysfunction by potent pancreatic exocrine supplements in patients with chronic pancreatitis. Journal of clinical gastroenterology 32: 319-323.

12. Ewald N, Bretzel RG, Fantus IG, Hollenhorst M, Kloer HU (2007) Pancreatin therapy in patients with insulinâ€ treated diabetes mellitus and exocrine pancreatic insufficiency according to low fecal elastase 1 concentrations. Results of a prospective multiple centre trial. Diabetes/metabolism research and reviews 23: 386-391.

13. Pierzynowski S, Burrin D (2004) Use of alpha-ketoglutaric acid for the treatment of malnutrition or high plasma glucose condition. Google Patents.

14. Sliwa E, Dobrowolski P, Tatara MR, Pierzynowski SG (2007) Alphaketoglutarate partially protects newborns from metabolic changes evoked by chronic maternal exposure to glucocorticoids. Journal of Pre-Clinical and Clinical Research 1: 055-059.

15. Christoffersen B, Ribel U, Raun K, Golozoubova V, Pacini G (2009) Evaluation of different methods for assessment of insulin sensitivity in Gattingen minipigs: introduction of a new, simpler method. American Journal of PhysiologyRegulatory, Integrative and Comparative Physiology 297: R1195-R1201.

16. Pierzynowski S, Western B, Karlsson B, Nilsson B, Svendsen J (1988) Pancreatic cannulation of young pigs for long-term study of exocrine pancreatic function. Canadian journal of animal science 68: 953-959. 
Citation: Pierzynowski SG, Goncharova K, Woliński J, Prykhodko O, Weström B, et al. (2016) Enteral Pancreatic-like Enzymes of Microbial Origin affect Insulin Release during an Intravenous Glucose Tolerance Test. J Diabetes Metab 7: 681. doi:10.4172/2155-6156.1000681

Page 8 of 8

17. Guilloteau P, Zabielski R, Hammon HM, Metges CC (2010) Nutritional programming of gastrointestinal tract development Is the pig a good model for man? Nutr Res Rev 23: 4-22

18. Gewert K, Holowachuk SA, Rippe C, Gregory PC, Erlanson-Albertsson C, et al. (2004) The enzyme levels in blood are not affected by oral administration of a pancreatic enzyme preparation (Creon 10,000) in pancreas-insufficient pigs. Pancreas 28: 80-88.

19. Fedkiv O, Rengman S, Westrom BR, Pierzynowski SG (2009) Growth is dependent on the exocrine pancreas function in young weaners but not in growing-finishing pigs. J Physiol Pharmacol 60 Suppl 3: 55-59.

20. Rengman S, Fedkiv O, Botermans J, Svendsen J, Western B (2009) An elemental diet fed, enteral or parenteral, does not support growth in young pigs with exocrine pancreatic insufficiency. Clinical nutrition 28: 325-330.

21. Dabek M, Kruszewska D, Filip R, Hotowy A, Pierzynowski A (2005) Ketoglutarate (AKG) absorption from pig intestine and plasma pharmacokinetics. Journal of animal physiology and animal nutrition 89: 419-426.

22. Hou Y, Wang L, Ding B, Liu Y, Zhu H, et al. (2010) Dietary ketoglutarate supplementation ameliorates intestinal injury in lipopolysaccharide-challenged piglets. Amino Acids 39: 555-564.

23. Moran A, Diem P, Klein DJ, Levitt MD, Robertson RP (1991) Pancreatic endocrine function in cystic fibrosis. J Pediatr 118: 715-723.

24. Nakajima K, Muneyuki T, Munakata H, Kakei M (2011) Revisiting the cardiometabolic relevance of serum amylase. BMC Res Notes 4: 419.

25. Nakajima K, Nemoto T, Muneyuki T, Kakei M, Fuchigami H, et al. (2011) Low serum amylase in association with metabolic syndrome and diabetes: $A$ community-based study. Cardiovasc Diabetol 10: 34 .

26. Nakajima K, Oshida H, Muneyuki T, Saito M, Hori Y, et al. (2013) Independent association between low serum amylase and non-alcoholic fatty liver disease in asymptomatic adults: a cross-sectional observational study. BMJ open 3 : e002235.

27. Saupecka M, WoliÅski J, Prykhodko O, Ochniewicz P, Gruijc D, et al. (2012) Stimulating effect of pancreatic-like enzymes on the development of the gastrointestinal tract in piglets. J Anim Sci 4: 311-314.

28. Prykhodko O, Fedkiv O, Westrern BR, Pierzynowski SG (2014) Effects on gut properties in exocrine pancreatic insufficient (EPI) pigs, being growth retarded due to pancreatic duct ligation at 7 weeks but not at 16 weeks of age. Advances in medical sciences 59: 74-80.

29. Borowitz D, Goss CH, Limauro S, Konstan MW, Blake K, et al. (2006) Study of a novel pancreatic enzyme replacement therapy in pancreatic insufficient subjects with cystic fibrosis. The Journal of pediatrics 149: 658-662.

30. Zhao P, Metcalf M, Bunnett NW (2013) Biased signaling of protease-activated receptors. Frontiers in endocrinology 5: 67-67.

31. Rothmeier AS, Ruf W (2012) Protease-activated receptor 2 signaling in inflammation. Semin Immunopathol 34: 133-149.

32. Ihara $H$, Sasaki T, Tsuboi $A$, yamagata $H$, Tsukagoshi $N$ (1985) Complete nucleotide sequence of a thermophilic alpha-amylase gene: homology between prokaryotic and eukaryotic alpha-amylases at the active sites. Journal of biochemistry 98: 95-103.

33. Pierzynowski S, Szwiec K, Valverde Piedra J, Gruijc D, Szymanczyk S (2012) Exogenous pancreatic-like enzymes are recovered in the gut and improve growth of exocrine pancreatic insufficient pigs. Journal of animal science 90 324-326.

34. Pierzynowski SG, Weström BR, Svendsen J, Svendsen L, Karlsson BW (1995) Development and regulation of porcine pancreatic function. Int J Pancreatol 18: 81-94

35. Yao K, Yin Y, Li X, Xi P, Wang J, et al. (2012) Alpha-ketoglutarate inhibits glutamine degradation and enhances protein synthesis in intestinal porcine epithelial cells. Amino Acids 42: 2491-2500.

36. Cynober L, Coudray-Lucas C, De Bandt J, Guachot J, Aussel C, et al. (1990) Action of ornithine alpha-ketoglutarate, ornithine hydrochloride, and calcium alpha-ketoglutarate on plasma amino acid and hormonal patterns in healthy subjects. Journal of the American College of Nutrition 9: 2-12.

37. Buddington RK, Pajor A, Buddington KK, Pierzynowski S (2004) Absorption of Ît-ketoglutarate by the gastrointestinal tract of pigs. Comparative Biochemistry and Physiology Part A: Molecular \& Integrative Physiology 138: 215-220.

38. Filip R, Kruszewska D, Piedra JLV, Studzi Prandial and postprandial exocrine pancreatic secretion after duodenal infusion of alpha-ketoglutarate, formic acid and potassium di-formate in pigs. Journal of Pre-Clinical and Clinical Research 1: 060-064.

39. Maechler $P$, Wollheim CB (1999) Mitochondrial glutamate acts as a messenger in glucose-induced insulin exocytosis. Nature 402: 685-689. 